\title{
A Comparative Study of the Situation of Supported Employment in Europe
}

\author{
Stephen Beyer ${ }^{\star}$, Francisco de Borja Jordán de Urríes ${ }^{\dagger}$, and Miguel Angel Verdugo ${ }^{\dagger}$ \\ ${ }^{\star}$ Cardiff University, Welsh Centre for Learning Disabilities, Cardiff, Wales, UK; and 'University of Salamanca, Instituto Universitario \\ de Integracion en la Comunidad, Salamanca, Spain
}

\begin{abstract}
Agencies offering supported employment (SE) in the European Union (EU) were surveyed using a Web-based questionnaire in 2006. Responses were obtained from 184 organizations, primarily from Finland, Spain, and the United Kingdom (UK). The majority of respondents offered a wide range of services with $83 \%$ offering SE and about half having begun offering it in the last 5 years. The data showed many organizations offering services in addition to SE (e.g., vocational training or sheltered work provision). There was significant variation in provision of key elements of SE, particularly workplace support. This may disadvantage people with intellectual disabilities (ID). Funding of SE varied across areas, with $22 \%$ overall reliant on short-term European funding. People with ID were the largest group of users by "minorities" in Finland and Spain. Most worked more than 24 h per week, with only a minority having permanent contracts. Hours of support were generally low. The authors conclude that funding for SE is fragile and that variations in the model used may disadvantage people with more severe ID, and thus lead to less effective SE. Fewer hours worked in the UK than elsewhere suggest a lack of harmonization of welfare benefit legislation provision across the EU, again affecting people with ID disproportionately. The study highlights the need for follow-up studies.
\end{abstract}

Keywords: disability policy, Europe, intellectual disabilities, supported employment, work

\section{INTRODUCTION}

Supported employment (SE) emerged in the United States during the 1980s as a work alternative to sheltered workshops and vocational training. Descriptions of the SE process vary in the number of key stages required (O'Bryan \& O'Brien, 1995; Trach \& Rusch, 1989; Wehman \& Kregal, 1985), but they can be usefully summarized under the following five areas: vocational profiling, job finding, job analysis and placement, job training, and followalong services.

Vocational profiling generally entails collecting enough information for each person with a disability to establish their work preferences and their skills, so that staff who find jobs can look for jobs that match. High-quality job tasters allow a person to gain knowledge of work places so that they can make job choices based on an understanding of what is required in work. Job finding entails locating jobs that match each person's work preferences and abilities using knowledge of the local labor market and approaching potential employers to obtain the job. This might include job carving to identify tasks from various jobs to meet a person's needs, or negotiating modifications to aspects of the job to suit the person.

Received October 30, 2008; accepted October 21, 2009

Correspondence: Stephen Beyer, Cardiff University, Welsh Centre for Learning Disabilities, Neuadd Merionnydd Heath Park, Cardiff CF14 4YS, Wales, UK. Tel: +44 029 20687206; Fax: +44 029 20687100; E-mail: beyer@cf.ac.uk
Job analysis and placement entails achieving an effective job match by generating as much information on the job and workplace to match that available for the individual from a vocational profile. Job training which involves placement in an ordinary job is seen not as an endpoint but a necessary first step in successfully learning a job, the supported employee being taught a specific job, in a specific work place, usually by a skilled job trainer or a co-worker providing natural support. Task training for people with substantial intellectual disabilities (ID) commonly involves breaking tasks down into component steps and the use of a prompting hierarchy by the trainer to give just enough information for the person to do the job without creating dependency. Lastly, follow-along services concern recognizing that many people with a disability will require ongoing support to help cope with changes in the workplaces (e.g., work routines, production processes, and personnel changes) and to support career development.

Evaluations of the benefits of SE schemes have been multidimensional but, in volume terms, are still mainly derived from research conducted on experiences in the United States. SE has generally been found to be successful compared with other models of vocational rehabilitation in relation to terms of wage levels (Lewis, Johnson, Bruininks, Kallsen, \& Guillery, 1992; Noble, Conley, Banerjee, \& Goodman, 1991; Verdugo, Jordán de Urríes, \& Vicent, 2007), increased self-esteem (Griffin, Rosenberg, \& Cheyney, 1996), job satisfaction (Test, Hinson, Solow, \& Keul, 1993), engagement in meaningful activity (Kilsby \& Beyer, 1996), self-determination (Wehmeyer, 1994), quality of life gains 
(McCaughrin, Ellis, Rusch, \& Heal, 1993), job retention (Beyer, Goodere, \& Kilsby, 1996; Blanck, 1994;), and cost benefit (Beyer et al., 1996; Lewis et al., 1992). Social interaction has been found to be similar to nondisabled co-workers (Beyer, Kilsby, \& Willson, 1995; Parent et al., 1992; Chadsey-Rusch et al., 1998), but more variation exists across studies in this area.

Following the awareness that it can offer an effective solution for community-based employment of people with disabilities, SE has been significantly developed in Europe since the 1990s, with the parallel creation of a network of national unions of SE and an overarching European Union of Supported Employment (EUSE, 2010). There has, however, been little systematic research in relation to the status of SE development across Europe. Spjelkavik and Evans (2007) noted the development of SE in Europe from a qualitative perspective. Some insight also comes from Organisation for Economic Co-operation and Development study of labor market strategies showing that, on average, the participation rate of persons with severe disabilities in the European Union (EU) workforce is under 35\% compared with $70 \%$ for workers without disabilities at that time (Van Lin, Prins, \& De Kok, 2002). There were significant differences in the extent to which countries used active labor market programs (i.e., schemes to improve integration into the labor force) rather than passive programs (i.e., provision of maintenance welfare benefits) to help people with disabilities who are not working. The shift from passive to active programs is quite recent and in some cases still ongoing.

Beyer, Hedeboux, Morgan, Van Regenmortel, and Samoy (2004) provide more specific insight into European trends in SE. They noted that the number of people with disabilities benefiting from SE seemed low for all EU member states, with levels of only a few hundred persons by 1998. Exceptions were observed in Denmark $(n=1,853)$, the Netherlands $(n=3,306)$ and in the UK $(n=16,100)$, and in Germany where close to 1 in 1,000 working age people are found on such programs. The authors concluded that the broad trend in the EU is toward supporting people with disabilities in community jobs and away from maintaining segregated workshops-but that in 1998, the situation was still that many more resources were invested in specialist workshop provision than in community provision.

Some national studies of SE have been conducted in the past that have provided largely noncomparable data for some countries because of measures or concentration on specific client groups. These include England and Wales (Beyer et al., 1996; Beyer, 2001; Beyer, Thomas, \& Thornton, 2003), Finland (Saloviita \& Pirttimas, 2007), Norway (Spjelkavik, Frøyland, \& Evans, 2004), the Netherlands (van Erp et al., 2007), Scotland (Hunter \& Ridley, 2007; Ridley, Hunter, \& Infusion Co-operative, 2005), and Spain (Jordán de Urríes \& Verdugo, 2003; Jordán de Urríes, Verdugo, \& Vicent, 2005a; Verdugo \& Jordán de Urríes, 2001; Verdugo, Jordán de Urríes, \& Bellver, 1998b; Verdugo, Jordán de Urríes, Bellver, \& Martínez, 1998a).

A number of key issues for European SE efforts emerge from this work. We see a shift from the original focus on people with ID to other groups of people with disabilities or marginalization. The idea of using job coaches has been seen by governments as a new way of helping marginalized, rather than disabled, groups into employment. This has shifted the focus from SE as a process for including the most excluded people to a focus on the more able (albeit socially disadvantaged), the danger being that people with significant ID are again left without help (Saloviita \& Pirttimas, 2007). The investment by governments has been greater in day centers and sheltered workshops than in community-based employment in many parts of Europe. The use of SE with marginalized groups does not assist people with higher support needs to transition away from segregated provision. In this regard, there is a lack of leadership and few consistent frameworks from which to commission and audit the performance of SE (Ridley et al., 2005). There remains a lack of skilled training in some of the SE workforce, and a lack of commitment on the part of employers (Spjelkavik et al., 2004).

While some national unions of SE do carry out internal studies of their member organizations, there is currently no central database on SE as defined here. Thus, the aim of this study was to carry out a descriptive, quantitative study of the situation of SE in the EU, collecting cross-national and consistent data by means of a specially designed survey. The objective was to obtain data for better understanding of the situation, and the framing of policy development for SE in Europe.

\section{METHOD}

\section{Participants}

The European Union of Supported Employment (EUSE) is an umbrella organization of 19 national associations of SE in Europe. It is governed by an executive council, which agreed to support the study and promote it to its constituent country unions, and through them, to their member organizations operating SE intiatives. To begin the process, a working group within the EUSE arrived at a consensus among local associations on the different terms and concepts used in the questionnaire and aided in the development of the study questionnaire. The questionnaire was then translated into Czech, Dutch, English, Finnish, Italian, Portuguese, and Spanish and configured for online access. Announcement of the study was carried out by e-mail through EUSE in coordination with the Instituto Universitario de Integracion en la Comunidad and the Welsh Centre on Learning Disabilities. Each of the EUSE national organizations was asked to promote the survey among its members. The initial announcement was followed by a series of regular e-mail reminders to organizations throughout data gathering period. Data were collected between October and December 2006, and a report was completed in August of 2007.

\section{Types of Organization}

A number of the constituent agencies offered more than SE, but the quantitative data collected related only to their provision of SE, whether or not the agency provided other types of services. The definition of SE used in the questionnaire was stated as follows: "Jobs with ordinary community employers found and supported by an employment agency that can offer on-the-job support through a Job Coach (sometimes called employment specialist, employment officer, or employment consultant). Also called the 'Place, Train, and Maintain Model', it can provide a high level of 
involvement in profiling the workers needs, finding and analysing jobs, providing systematic training and advocacy in the job site."

\section{Data Collection and Analysis}

A Web completion questionnaire was developed, where each agency could create a unique identifier and input its data directly over several sessions, if needed. The questionnaire included definitions of terms and was available online in seven languages (Jordán de Urríes, Beyer, \& Verdugo, 2007). Data were collected, stored, and then analyzed using SPSS 15 (SPSS Inc., Chicage, IL, USA).

\section{Measures}

The data requested of agencies were for the year 2006. The questionnaire was based on one developed and used for some time in Spain (Jordán de Urríes, Verdugo, Jenaro, Crespo, \& Caballo, 2005b) and consisted of 36 items divided into six sections: Section 1: Organization (consisting of 11 questions that named the organization and, if appropriate, the program within it, along with contact information); Section 2: Services offered and quality (consisting of eight questions that described what employment and vocational rehabilitation services they offered, and which of these had funding for the next 12 months; respondents were also asked to describe the start date of their SE service, the elements of the SE model they delivered, and how they evaluated quality); Section 3: Users (consisting of nine questions describing the total number of people in jobs through the work the SE service, the hours they worked, average wages, levels of support, and how many jobs were found in the last 12 months); Section 4: Professionals (consisting of five questions describing the staff of the SE organization, their wages, and arrangements for training within the SE agency); Section 5: Funding (consisting of three questions describing the sources of funding and costs of the SE service); and Section 6; (consisting of additional information or comments).

\section{RESULTS}

\section{The Organizations}

Information obtained from EUSE recognizes 2,177 member agencies in the full range of 17 EUSE member countries (EUSE, 2010). Membership can involve individuals as well as agencies, and registration practice varies between country unions. Completed questionnaires were received from 184 organizations from 10 countries; EUSE identifies 1,333 constituent "members" in these 10 respondent source countries. As this was an open response survey, the true response rate is uncertain (of the 10 respondent counties, the response rate was about 14\%) and relatively low and it was clearly biased toward certain countries. Responses from organizations in Spain (61\%), Finland (14\%), and the UK $(12 \%)$ made up $87 \%$ of the data (Table 1$)$. The sample within this grouping was, however, large enough to permit
TABLE 1

Number of organizations responding to the survey

\begin{tabular}{lrr}
\hline \hline Country & Total & $\%$ \\
\hline Austria & 2 & 1 \\
Czech Republic & 13 & 7 \\
Finland & 25 & 14 \\
Hungary & 1 & $<1$ \\
Irish Republic & 4 & 2 \\
Netherlands & 1 & $<1$ \\
Portugal & 3 & 2 \\
Rumania & 1 & 61 \\
Spain & 112 & 12 \\
United Kingdom & 22 & 100 \\
Total & 184 & \\
\hline
\end{tabular}

some conclusions to be drawn on the situation of SE in Europe. To aid in the analysis, we clustered the remaining responses of the 25 organizations into the category of "other countries."

We found that $79 \%$ of those organizations offering SE had begun doing so for the past 10 years and some $53 \%$ for over the past 5 years. The data tell us that the majority of SE services are relatively recent. In addition, as noted in Table 2, most organizations reported offering or operating other services as well, such as vocational training $(40 \%)$, occupational centers $(32 \%)$, day center provision $(28 \%)$, or sheltered workshops $(25 \%)$. We observed that significant numbers of organizations in Finland, UK, and the rest of Europe offered SE as well as vocational training. Spain has similar levels, with its organizations offering vocational training (30\%), occupational centers $(37 \%)$, and sheltered work provision $(31 \%)$. Conversely, the organizations in the UK reported the lowest levels (9\%). Overall, few organizations reported "social firms" (13\%) among their offerings, except for the UK (36\%). "Social firms" are commercial businesses created for the social purpose of providing employment opportunities within a supportive working environment for people who would otherwise be severely disadvantaged in the open labor market.

\section{SE Offered}

Of the organizations responding, $83 \%$ noted that they offered a full SE service (e.g., being able to offer a job coach or equivalent, profiling a workers needs, finding and analyzing jobs, and providing systematic training and advocacy in the job site). The remainder reported delivering only elements of the SE process. The number offering a service fully consistent with our definition of SE varied significantly, from $86 \%$ in Spain and the UK to $68 \%$ in the "Rest of Europe" group (Table 3). Also, the elements of the SE process offered by organizations differed significantly among countries (Figure 1). Use of vocational profiling ranged from $60 \%$ in Finland to $86 \%$ in Spain, a significant range. Individual planning for employment was also low in Finland (64\%) compared with other areas $(82-85 \%)$. The provision of workplace training provision ranged from $64 \%$ of organizations in Finland to $77 \%$ in 
TABLE 2

Services provided by organizations

\begin{tabular}{lccrr}
\hline \hline Services provided & Spain & Finland & United Kingdom & Rest of Europe \\
\hline Supported employment (\%) & 86 & 68 & 86 & 81 \\
Vocational training (\%) & 30 & 68 & 55 & 46 \\
Day center (\%) & 28 & 44 & 14 & 23 \\
Occupational center (\%) & 37 & 48 & 5 & 15 \\
Social firm/enterprise (\%) & 7 & 12 & 36 & 15 \\
Sheltered/special employment center(\%) & 31 & 24 & 9 & 15 \\
Total organizations & 112 & 25 & 22 & 25 \\
\hline
\end{tabular}

TABLE 3

Percentage of organizations with expected funding for the service for 12 months

\begin{tabular}{lccrr}
\hline \hline Services provided & Spain (\%) & Finland (\%) & United Kingdom (\%) & Rest of Europe (\%) \\
\hline Supported employment & 62 & 71 & 84 & 57 \\
Vocational training & 79 & 71 & 92 & 65 \\
Day center & 94 & 73 & 100 & 72 \\
Occupational center & 93 & 67 & 100 & 83 \\
Social firm/enterprise & 63 & 67 & 75 & 100 \\
Sheltered/special employment center & 91 & 50 & 50 & 75 \\
\hline
\end{tabular}

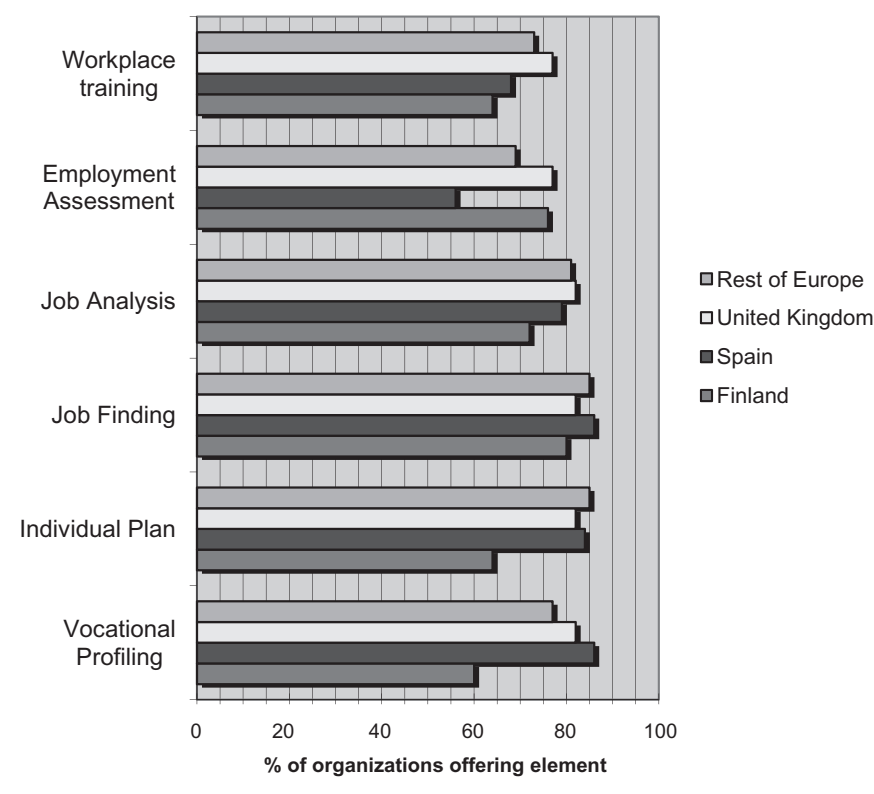

FIGURE 1

Provision of elements of the supported employment process. the United Kingdom. These data raise a concern as it appears that the employment needs of adults with ID may not be fully addressed.

\section{Funding}

Our data indicated that many SE schemes run by the respondent agencies are relatively recent. We also know that in tough economic times, public funding support for SE may be the most fragile in terms of public funding for people with severe disabilities. Our data revealed that only $65 \%$ of the respondent organizations offering SE noted that they have assured funding for this service for the next 12 months, compared with $85 \%$ reporting assured funding for sheltered or special employment centers over the same period. However, we observed variability in this pattern across countries. For example, in the UK, funding for SE appeared to be more stable, with funding for sheltered employment centres being more fragile, a pattern similar to that observed in Finland. Conversely, in Spain, SE and social firms have equally fragile funding compared with other services, while in the rest of Europe SE and vocational training are the most fragile.

We also asked organizations about the sources of their funding (Table 4). Overall, national (30\%) and regional (36\%) government funding sources were most common, with European (22\%) and local (12\%) sources less common. There were variations in these data among countries, with the UK relying heavily on local (36\%) and European (64\%) funding sources, but with 
TABLE 4

Source of funding for the organization

\begin{tabular}{lcccr}
\hline \hline Funding source & Spain (\%) & Finland (\%) & United Kingdom (\%) & Rest of Europe \\
\hline European & 18 & 0 & 64 & 40 \\
National & 13 & 95 & $<1$ & 55 \\
Regional & 54 & $<1$ & $<1$ & 4 \\
Local & 15 & 5 & 36 & 30 \\
\hline
\end{tabular}

TABLE 5

Key indicators of use of supported employment

\begin{tabular}{|c|c|c|c|c|}
\hline Spain & Finland & United Kingdom & Rest of Europe & All \\
\hline 11 & 12 & 36 & 29 & 35 \\
\hline 1 & 4 & 37 & 4 & 5 \\
\hline 18 & 5 & 42 & 28 & 22 \\
\hline 81 & 91 & 20 & 68 & 73 \\
\hline 24 & 33 & 21 & 32 & 26 \\
\hline 68 & 39 & 67 & 57 & 65 \\
\hline 8 & 29 & 12 & 11 & 9 \\
\hline 32 & 24 & 77 & 65 & 44 \\
\hline \multicolumn{5}{|c|}{ Levels of support (\%) } \\
\hline
\end{tabular}

very little national government funding provision $(<1 \%)$. Conversely, Finnish respondent organizations noted receiving $95 \%$ of their support from national sources and Spain's organizations reporting being heavily reliant on regional funding (54\%).

\section{Users of SE}

There were some interesting trends concerning the extent to which people with ID are using SE (Table 5). Overall, across all respondents, people with ID represented the largest group (35\%) of users. In the UK, respondents noted that this group makes up $36 \%$ of their clientele, compared with only 11 and $12 \%$, respectively, in Spain and Finland. In Finland, the largest user group (54\%) are people who are "socially excluded" rather than those having a physical or cognitive disability.

We observed that the hours users spent in SE varied. Most respondents noted that their clientele work mainly more than 24 h per week (73\% overall). The exception was in the UK, where SE remains mainly a part-time activity, with respondents noting that about $37 \%$ of their clientele worked less than $12 \mathrm{~h}$ per week. Apparently, this difference is the result of the working patterns of people with ID in the UK, where only $11 \%$ work more than $24 \mathrm{~h}$ per week, compared with $62 \%$ for the overall European data population. For other client groupings, the trend is consistent across Europe, with most working over $24 \mathrm{~h}$ per week. Contracts for people in SE also differ, the general position being that permanent contracts are in the minority (44\%). The UK has the highest levels (77\%), with Finland (24\%) and Spain (32\%) relying much more on temporary contracts. Levels of support are also generally low, with $65 \%$ of workers receiving support of less than $5 \mathrm{~h}$ per week. This is a general European trend apart from Finland where $74 \%$ of people receive 5 to $10 \mathrm{~h}$ of support per week.

\section{CONCLUSIONS}

SE is a foundational mechanism for inclusion of people with ID in the labor market. SE schemes coexist within organizations along with a variety of services not primarily devoted to promoting social inclusion. SE is also a relatively new phenomenon, with only slightly over half of the disability having started SE schemes within the past 5 years. This is consistent with earlier findings that 
noted there was more of a focus on sheltered employment prior to 1998, but that now there is a trend toward communitybased employment and use of active labor market involvement strategies. We believe that the coexistence of SE with other programs within the respondent organizations, taken with the relative financial stability of these other services, represents a transition within these organizations toward community-based employment.

Funding for SE is fragile in general terms, and the differences in assurances of at least 12 months forward funding-in some countries-suggest that the availability of community-based employment is being given differential priority across Europe. The emphasis on European funding of SE is also of concern as experience has been that European funding is primarily start-up funding that lasts for only a few years and which then needs to be naturalized into longer term national-derived funding sources if SE services are to continue and grow. The nature of these funding vagaries adds to the fragility of SE within Europe. The EU and governments at their different levels will need to promote and implement the necessary policies and appropriations to secure a stable flow of financial resources if SE services are to be equitably available across the EU to people with ID.

Our survey revealed a lack of consistency in delivery of the SE model across organizations. SE relies on clear mechanisms, based on solid research and experience. Our data indicate that a proportion of the organizations do not offer the most basic set of SE services, including vocational profiling, personalized planning, analysis of job positions, and training in the workplace-as these services are provided by proportions that range from 60 to $85 \%$. Failure to deliver the full model of SE can reduce the ability of SE to serve people with more severe disabilities. Also, the driving force for cost-effectiveness in SE is the ability progressively to reduce hours of support over time, and increase the number of people placed into jobs in the labor market.

The data we have are positive, suggesting that levels of support are low overall, consistent with the dynamic adjustment of support. However, without the ability to deliver the full model of SE with skill, there is a danger that people with higher support needs will need ongoing support for considerable time and that SE will cease to develop and evolve.

The place of people with ID within SE is interesting. The experience in the United States has been that SE was designed around the needs of people with ID, and that other client groups only began to use SE as an individualized service later, possibly with some adaptation of the method. In our European sample, people with ID are still the largest group, but SE is provided to many other client groups via the same organizations. The involvement of people who are "socially excluded" is interesting as this has not been a major feature of provision in the United States, largely because funding has been mandated by laws dedicated to aiding people with ID and the program was designed specifically to serve people whose disability was their main barrier to entering the competitive labor market. The results of this survey echo data noted by others in describing a widening of the client focus of SE in Europe. The dilemma for organizations is that although they are dependent of general funds to support their SE efforts, they must also ensure that people with greater degrees of disability and need are not excluded as a result.
The hours people worked differed across countries. This is not without consequences as the hours that people work has an impact on the speed of learning a job, on integration within the workforce, and on the financial benefit of employment to the individual. The shorter hours worked by people with ID in the UK would suggest that a lack of harmonization of welfare benefit provision across the EU is having an impact on the hours that people feel they can work and be better off. This may particularly affect people with ID, who can be on higher levels of welfare benefits compared with people, for example, who are experiencing social exclusion.

Differences in the type of contracts offered are also important. Contracts in the UK relate to UK employment legislation and are permanent after a statutory probationary period. In contrast, there is greater use of temporary contracts in the rest of the EU that can build insecurity into the transition into employment for the workers concerned. These arrangements are complex; for example, in Spain there are at least five different types of temporary contracts, and in Finland there are many different reasons why a temporary or fixed-term contract can be formed. The key to inclusion is that SE workers are treated the same as other workers in any particular workplace, when doing the same work. When it is appropriate, efforts must continue to ensure that there are equal rights to full-time contracts across the EU and that barriers to this are progressively removed.

This study is the first attempt to describe the situation of SE in Europe using a common measurement framework. Although it provides an overview, the results should be treated with caution as they are not fully representative of Europe as a whole. There is a need for further follow-up research to assist national governments and institutions to understand the situation of SE and to help extend the opportunity it offers people with intellectual and other disabilities to join the mainstream labor market.

\section{REFERENCES}

Beyer, S. (2001). Trends in supported employment. Tizard Learning Disabilities Review, 6, 36-39.

Beyer, S., Kilsby, M., \& Willson, C. (1995). Interaction and engagement of workers in supported employment: A British comparison between workers with and without learning disabilities. Mental Handicap Research, 8, 137-155.

Beyer, S., Goodere, L., \& Kilsby, M. (1996). The costs and benefits of supported employment agencies: Findings from a national survey. Employment Service Research Series, No. 37. London: Stationery Office.

Beyer, S., Thomas, J., \& Thornton, P. (2003). The net costs and individual benefits of the supported employment programme. Report WAE 152. Sheffield, UK: Department of Work and Pensions Research Management.

Beyer, S., Hedeboux, G., Morgan, C., Van Regenmortel, T., \& Samoy, E. (2004). Inter-national reflection: A report on effective approaches to vocational training and employment for people with learning disabilities from the LABOr project. Brussels: European Association of Service Providers for Persons with Disabilities (EASPD).

Blanck, P. D. (1994). Employment integration, economic-opportunity, and the Americans with Disabilities Act: Empirical-study from 19901993. Iowa Law Review, 79, 853-923.

Chadsey-Rusch, J., Gonzalez, P., Tines, J., \& Johnson, R. (1998). Social ecology of the workplace: Contextual variables affecting social inter- 
action of employees with and without mental retardation. American Journal of Mental Retardation, 94, 141-151.

van Erp, N., Femke, B., Giesen, M. A., van Weeghel, J., Kroon, H., Michon, H., et al. (2007). A multisite study of implementing supported employment in the Netherlands. Psychiatric Services, 58, 14211426.

European Union of Supported Employment. (2010). About EUSE. Retrieved March 7, 2010, from http://www.euse.org/

Griffin, D. K., Rosenberg, H., \& Cheyney, W. (1996). A comparison of self-esteem and job satisfaction of adults with mild mental retardation in sheltered workshops and supported employment. Education and Training in Mental Retardation and Developmental Disabilities, 31, 142-150.

Hunter, S., \& Ridley, J. (2007). Supported employment in Scotland: Some issues from research and implications for development. Tizard Learning Disability Review, 12, 3-13.

Jordán de Urríes, F.-B., \& Verdugo, M.-A. (2003). El empleo con apoyo en España: Análisis de variables que determinan la obtención y mejora de resultados en el desarrollo de servicios [The use with support in Spain: Analysis of variables that determine the obtaining and improvement of results in the development of services]. Madrid: Real Patronato sobre Discapacidad.

Jordán de Urríes, F.-B., Verdugo, M.-A., \& Vicent, C. (2005a). Análisis de la evolución del empleo con apoyo en España [Analysis of the evolution of the use of support in Spain]. Madrid: Real Patronato sobre Discapacidad.

Jordán de Urríes, F.-B., Verdugo, M.-A., Jenaro, C., Crespo, M., \& Caballo, C. (2005b). Supported employment and job outcomes: Typicalness and other related variables. Work, 25, 221-229.

Jordán de Urríes, F.-B., Beyer, S., \& Verdugo, M.-A. (2007). A comparative study of the situation of supported employment in Europe. Salamanca: Instituto Universitario de Integracion en la Comunidad, University of Salamanca.

Kilsby, M., \& Beyer, S. (1996). Engagement and interaction: A comparison between supported employment and day service provision. Journal of Intellectual Disability Research, 40, 348-357.

Lewis, D. R., Johnson, D. R., Bruininks, R. H., Kallsen, L. A., \& Guillery, R. P. (1992). Is supported employment cost-effective in Minnesota? Journal of Disability Policy Studies, 3, 67-92.

McCaughrin, W. B., Ellis, W. K., Rusch, F. R., \& Heal, L. W. (1993). Cost-effectiveness of supported employment. Mental Retardation, $31,41-48$.

Noble, J. H., Conley, R. W., Banerjee, S., \& Goodman, S. (1991). Supported employment in New York State: A comparison of benefits and costs. Journal of Disability Policy Studies, 2, 39-73.

O’Bryan, A., \& O'Brien, J. (1995). Supported employment quality assurance. Manchester: National Development Team.
Parent, W. S., Kregel, J., Metzler, H. M. D., \& Twardzik, G. (1992). Social integration in the workplace: An analysis of the interaction activities of workers with mental retardation and their coworkers. Education and Training in Mental Retardation, 27(1), 28-38.

Ridley, J., Hunter, S., \& Infusion Co-operative. (2005). Go for it! Supporting people with learning disabilities and/or ASD in employment. Edinburgh: Scottish Executive.

Saloviita, T., \& Pirttimas, R. (2007). Surveying supported employment in Finland: A follow-up. Journal of Policy and Practice in Intellectual Disabilities, 4, 229-234.

Spjelkavik, Ø., \& Evans, M. J. (2007). Impression of supported employment. A study of some European supported employment services and their activities. Oslo: Work Research Institute.

Spjelkavik, Ø., Frøyland, K., \& Evans, M. J. (2004). Supported employment in Norway - a national mainstream programme. Oslo: Work Research Institute.

Test, D. W., Hinson, K. B., Solow, J., \& Keul, P. (1993). Job satisfaction of persons in supported employment. Education and Training in Mental Retardation and Developmental Disabilities, 28, 38-46.

Trach, J. R., \& Rusch, F. R. (1989). Supported employment program evaluation: Evaluating degree of implementation and selected outcomes. American Journal on Mental Retardation, 94, 134-140.

Van Lin, M., Prins, R., \& De Kok, J. (2002). Active labour market programmes for people with disabilities. Fact and figures on use and impact. Zoetermeer, The Netherlands: Eim Business \& Policy Research.

Verdugo, M.-A., \& Jordán de Urríes, F.-B. (2001). Panorámica del Empleo con Apoyo en España [Overview of supported employment in Spain]. Madrid: Real Patronato sobre Discapacidad.

Verdugo, M. A., Jordán de Urríes, F. B., Bellver, F., \& Martínez, S. (1998a). Supported employment in Spain. Journal of Vocational Rehabilitation, $11,223-232$.

Verdugo, M.-A., Jordán de Urríes, F.-B., \& Bellver, F. (1998b). Situación actual del Empleo con Apoyo en España [Present situation of supported employment in Spain]. Siglo Cero, 29, 23-31.

Verdugo, M.-A., Jordán de Urríes, F.-B., \& Vicent, C. (2007). SEMECA, Sistema de evaluación multicomponente de empleo con apoyo: Aplicación al modelo de empleo con apoyo de la Comunidad de Madrid [System of multicomponent evaluation of supported employment: Application of the support model in Madrid]. Salamanca: University of Salamanca, INICO.

Wehman, P., \& Kregal, J. (1985). A supported work approach to competitive employment for individuals with moderate and severe handicaps. Journal of the Association for Persons with Severe Handicaps, 10, $3-11$.

Wehmeyer, M.-L. (1994). Employment status and perceptions of control of adults with cognitive and developmental disabilities. Research in Developmental Disabilities, 15, 119-131. 